\title{
The Cataloging Process in the University Library: A Pro- posal for Reorganization
}

\section{Mr. Lund is librarian, Duke University Library.}

A MONG the recent developments in the catalog and the cataloging process $y$ there are two that will undoubtedly be of the greatest significance to those concerned with the organization and administration of university ${ }^{1}$ libraries. The one is the division of the dictionary catalog into an author-title catalog and a subject catalog ; the other, the division of the cataloging department into a descriptive cataloging section and a subject cataloging section. Neither of these, however, is properly a division, but they represent, rather, the resolution of the catalog and the cataloging process into their original component parts. Furthermore, although the two developments have so far apparently been independent of each other, ${ }^{4}$ there is a very close correspondence, on the one hand, be-

1 The university library is here considered in its function as a scholarly reference and research library. This function comprises service to faculty members, research workers, graduate students, and "major" field during the junior and senior years. The other function of a university library, that of providing library service for the general education program of undergraduates during the freshman and sophomore years and part of the junior and senior years, though certainly no less important, is entirely distinct from the former function and properly requires separate organization and administration.

2 This division has recently been made at the University of California (1938), Duke University (1940), the University of Pennsylvania (r94I), and elsewhere.

${ }^{3}$ This division has been made, among other places, at the New York Public Library and the Library of Congress.

4 There seems to be no example as yet of the two occurring in any one library. tween the author-title catalog and the descriptive cataloging section, and on the other hand, between the subject catalog and the subject cataloging section.

As to the division of the dictionary catalog, we might very well ask why it did not begin earlier. For we have certainly been aware that author-title and subject entries were intended to serve entirely different purposes ${ }^{5}$ - the former to locate books already identified by author or title and the latter to identify books on particular subjects-and since it is just as useful to keep unlike things apart as it is to keep like things together, a priori logic would certainly favor the separation and place the burden of proof on those who proposed combining the two. ${ }^{6}$ And even as a mere practical device for reminding us of the distinct function of the two types of entry and aiding us in adapting each to its own

${ }^{\circ} \mathrm{Cf}$. Mann, Margaret. Introduction to the Cataloging and Classification of Books. Chicago, 19.30, p. I 35 ff.; and Bishop, William Warner. Practica Baltimore, I 924 , p. 37 ff.

- It is not easy to determine from the available literature exactly when and why the dictionary form was adopted. One explanation is that the dictionary catalog did not evolve from the combination of catalog did not evolve from the combination of separate author-title and alphabetical subject catalogs, but rather that it developed from the author-title catalog alone by the gradual increase in title, in
verted title, catchword, and other added entries-the accompanying subject catalog in classified form then disappearing as it was superseded by the subject entries in the author-title catalog. Cf. Cutter, Charles A "Lies in the autic Libraries in the A. Library Catalogs. Public Libraries in the United States of America. . Special report, De partment of the Interior, Bureau of Education, pt. I. The Card Catalog in Libraries in the U.S. before 1876. (M.S. in L.S. thesis, U. of Illinois, 1938), p. 31-34. 
particular purpose, the division would likewise seem justified. Furthermore, we have seen that much of the talk about simplifying and reducing the cost and complexity of the dictionary catalog, without changing its basic form, has been of little avail.

Similarly, we might ask why our recognition of the two distinctly different types of work that make up the cataloging process have not brought about their separation before now. On the one hand, there is the bibliographical description of the book, with the making of the usual author, title, and other added entry cards, and on the other, the entirely different process of examining the subject matter of the book and determining the subject headings and the classification number under which it belongs. ${ }^{7}$ It is not that we have been unwilling to create additional departments or sections-in fact, it would seem that nothing short of an active desire for a new department could explain the setting up, as is sometimes done, of a separate department for classification, apart from the regular catalog department where the subject headings are assigned. At any rate, with the division into descriptive cataloging and subject cataloging we have unquestionably made the first step in the rationalization of the whole cataloging process and are already further along than all our general talk about reducing the cost and complexity of cataloging could ever bring us. ${ }^{8}$

The next important development in the

7 The terms "descriptive cataloging" and "subject cataloging" are used to designate these two functions, as is done at the Library of Congress. European librarians have always kept the two separate, though they usually also separate the classification of the books on the shelves, since with them the latter is often not a matter of subject classification at all.

;8The failure to separate the two types of work has made it impossible to determine the professional l'evel of cataloging work and has likewise made it difficult to state the essential qualifications and the difficult to state the essential qualifications and the
proper training for a cataloger. For descriptive cataloging and subject cataloging each require their own answers to these questions.

JUNE, 1942 organization of the cataloging process will come when the interdependence of the two distinctions here mentioned is fully recognized. The two divisions will then be made in the same library and coordinated so that the descriptive cataloging section assumes the responsibility for the authortitle catalog and the subject cataloging section for the subject catalog. But even with this rationalization of the cataloging process itself, we shall merely have laid the foundation for the integration of this process with the other library functionsacquisition and service. For the descriptive cataloging done by the cataloging department cannot-in the interests of good management-be separated from the bibliographical work that must be done in the course of ordering and accessioning books, any more than-in the interests of good service-the subject cataloging done by the cataloging department can be separated from the subject work done by the reference staff, whether by means of the catalog, bibliographies, or their own knowledge.

\section{Proposal for Reorganization of Functions}

We come thus to a concrete proposal for the reorganization of those library functions included under the terms "technical processes" and "reference service." The proposal is simply that the ordering, accessioning, and descriptive cataloging processes be organized as a unified division and that subject cataloging and reference service be likewise organized as a unified division. Instead of creating an additional department by the separation of descriptive from subject cataloging, we shall thus have greatly reduced the number of administra-

\footnotetext{
2 With the exception of circulation service, we have taken into account all the major library functions. It must still be remembered, of course, that we ar dealing with the university library only as a research
} or scholarly library (see footnote $\mathrm{I}$ ). 
tive units and considerably simplified the organization of the library. This simplification, however, would be only one result of the proposed reorganization-the real justification rests on other considerations.

\section{Bibliographical Work and Descriptive Cataloging}

The close connection between the bibliographical work done in the process of ordering and the work that falls under the head of descriptive cataloging is readily apparent. Both involve the establishing of the entry and the identification and enumeration of the bibliographical and physical characteristics of the book. Most libraries have recognized this to the extent that they have attempted to prevent duplication of this work by the order and the cataloging departments. These attempts, however, have not proved particularly successful, and we still find the catalogers verifying the information secured by the order department if it is passed on to them or securing it anew if it is not passed on. Obviously there would be nothing to be lost and much to be gained by letting the same group prepare the catalog cards for a book for which they had already secured the information needed to check and order it. The simplification of records that would result would not be the least of the benefits of combining the two. Such a unified bibliographical department would have a subdivision for the clerical work of writing orders, checking bills, accessioning, etc., and perhaps also a subdivision for serial publications, without affecting its essential unity.

On the other hand, the combination of subject cataloging and reference work may require some explanation. Once we recognize two factors, however, the desirability of combining the two is obvious. In the first place, satisfactory subject cataloging and subject classification in a university library can only be done by persons with advanced academic training in the subjects they deal with; likewise, satisfactory reference service in a university library can only be done by persons who have academic training equal to those whom they serve. And since no one person can be competent in all or even very many fields, we have tried and are still trying to build up a staff of subject specialists in both the cataloging and the reference departments. The cost of this duplication of what must necessarily be high-salaried persons is unjustifiable under normal conditions and will become prohibitive in the period we are now entering. Furthermore, within the limits of the staff of each department, it is often impossible to secure coverage of the entire range of subject fields. But by combining the two we shall have eliminated this duplication and shall have available twice the number of people to cover the subject fields. ${ }^{10}$ In the second place, with the continual change in our subject divisions and approaches, the subject catalog of any particular collection can no longer be regarded as the final and complete guide to the subject matter of the collection-and certainly not to the subject material in other collections, which the scholar cannot ignore. The personal knowledge and service of the reference librarians and both general and special bibliographies are taking places of at least equal importance with the subject catalog. And proper coordination of the three can certainly best be secured by combining them in one administrative unit. In fact,

\footnotetext{
10 In addition to clerical help, each reference librarian in charge of a subject field or group may have one or more professional assistants or "understudies." In this way new reference librarians can be trained.
} 
the need for closer cooperation between the reference and cataloging departments has been felt for some time and efforts made to obtain it. Full combination of the two, however, has only become possible with the separation of subject from descriptive cataloging.

\section{Two Divisions}

In place of the usual order, cataloging, and reference departments, we then have two divisions - one of professional library work in a technical sense, covering bibliographical checking and descriptive cataloging, and the other of professional library work in an academic sense, covering subject cataloging and reference service. Under this organization the "processing" of a new book would be carried out somewhat as follows. Preparatory to placing the order, the bibliographers-as we shall call the assistants in the first division-will, as usual, check the entry, title, and imprint in order to identify the book and prevent duplication, and will make a preliminary card. When the book is received, this card will be revised as necessary to conform with the book, collation added, and the title, editor, and other added entries determined. The distribution of books among the several bibliographers may well be made by language, or by form, rather than by subject.

The book is then taken over by the reference librarian (or subject cataloger) in whose particular subject field it falls. The book is classified, subject headings are assigned-subject to some centralized revision-and the title entered in special lists or checked in printed bibliographies as the reference librarian sees fit. In the course of the subject cataloging procedure the reference librarians actually handle and have an opportunity to familiarize themselves with the books being added to the library in their respective fields. This is undoubtedly one of the greatest values of the arrangement.

The book then goes to the stacks, the cards are typed, traced, and filed-in the author-title catalog under the supervision of the bibliographers and in the subject catalog under the supervision of the reference librarians. ${ }^{11}$

\section{Use of L.C. Cards}

In this basic outline of the "processing" of books there are several points that may need amplification. There are also certain possible variations and innovations that merit consideration. ${ }^{12}$ Take first, for example, the question of using L.C. cards in a university library. There is no doubt that the information contained on L.C. cards is very helpful in the descriptive cataloging process and can save a good deal of time. But it is certainly reasonable to suppose that if university libraries had been making these cards instead of the $\mathrm{Li}$ brary of Congress, they would have arrived at a different form. And since university libraries cannot get L.C. cards for all their books, they are forced to choose between using L.C. form for the cards they make themselves and having two different types of cards in their catalogs. ${ }^{13}$ But perhaps we are worrying too much about the form of descriptive cataloging and perhaps consistency is the most

\footnotetext{
11 It may, of course, prove advisable, as is often done now, to file a temporary card in the author-title catalog as soon as the book is received and the entry established.

12 Some of these would be applicable to other forms of organization than the one here proposed.

13 There is, of course, also the delay and expense of ordering L.C. cards to be taken into account. We might have the benefit of the information on the card without necessarily adopting the card itself by simply using the depository catalog (as Harvard does) or if a depository catalog is not available, ordering one L.C. card for each book at the time the book itself is ordered. Another possibility would be for publishers to supply information for cataloging along with each book.
} 
important consideration. For descriptive cataloging is, after all, only one step in the cataloging process, even though the primary step. ${ }^{14}$

It is when we come to subject cataloging that we meet the real difficulty. Here the value of the subject headings and classification numbers on L.C. cards is very doubtful. For while it is possible to make universal descriptive cataloging rules, it is not possible to do the same satisfactorily for subject cataloging. Subject cataloging, including classification, cannot be done once and for all like descriptive cataloging but must be constantly changed and revised to meet changing approaches and conceptions. Each library must face and solve this problem in terms of its own peculiar conditions and purposes and the needs of its users-and also must be prepared to revise and change the solution continually. ${ }^{15}$ Perhaps centralized subject cataloging cannot even be satisfactory within a library that has departmental libraries and it should be left to each separate unit. One reason, undoubtedly, why libraries have used the subject headings on L.C. cards is that they have not had subject catalogers competent to work out their own system of subject headings. The combination of subject cataloging and reference work in one department should, however, make this possible.

\section{Classification}

The second point that needs special consideration is classification and its place in

14 We must guard against assuming that by solving the problem of a descriptive cataloging code or of centralized descriptive cataloging we have thereby solved the cataloging problem. This is particularly pertinent now that we are considering the new A.L.A. code and proposals by the L.C. Experimental Division of Library Cooperation for a centralized cardmaking bureau.

making bureau.il deny that our lists of subject headings and our classification schemes are in need of revision, if not complete reworking. the processing of a book. If the book could be classified by the descriptive catalogersinstead of the subject catalogers, as we have proposed-we could make a further improvement in the routine, for the descriptive catalogers could then file their cards in the author-title catalog as soon as the call number was added, before turning the book over to the subject catalogersthus eliminating perhaps the need for a temporary card. ${ }^{16}$ At the same time they could make, say, three or four extra cards to be sent along with the book, to which the subject catalogers could add subject headings before filing them in the subject catalog. But to have classification done by the descriptive catalogers would violate the basic principle by which we are proposing to reorganize the processing operations, because separating from the subject cataloging classifications would require descriptive catalogers with the same subject knowledge as the subject catalogers.

There is, however, one way in which classification could be done by descriptive catalogers with no special subject knowledge but it would mean either adopting a scheme of subject classification so broad that no particular academic knowledge would be required to classify a book by it, ${ }^{17}$ or else giving up subject classification on the shelves altogether and choosing

\footnotetext{
16 Tracings for added entries in the author-title catalog could be put on the shelflist card by the descriptive catalogers and then sent on to the subject catalogers who would trace their subject entries on it before it was filed in the shelflist.

17 This could very easily be worked out for the departmental libraries of a university library. The departmental libraries of a university library. The main library, just as the ordering is-the cards in the main library, just as the ordering is-the cards in the mental library" and filed, and then a certain number of subject cards (also some for the departmental library author-title file) going with the book to the departmental librarian (who functions as the reference librarian and subject cataloger in that field), and she would then do her subject cataloging and shelf she would then do her subject cataloging and shelf arranging as she saw best, independent of the main library or other departmental libraries. (Such an arrangement would parallel a national situation in which descriptive cataloging is done by a central
agency, but subject cataloging left to each individual library.)
} 
some factor other than subject as a basis for arranging the books in the stackssuch as order of accession, date of publication, country of origin, size, alphabetical sequence of authors' names, or a combination of any of these. There is more than a remote probability that we shall eventually come to the latter, and in any event, with detailed subject classification proving to be less and less useful ${ }^{18}$ and less and less permanent, some other system based on some more permanent characteristic should at least be considered. ${ }^{19}$

Another important point that can be discussed further is the manner of making subject entries. One of the chief obstacles to continual and regular revision of the subject catalog is undoubtedly the physical problem of changing the subject headings typed on the cards. But if subject headings were not actually typed or written on the cards and instead guide cards were used, the various titles could be refiled from time to time and new headings added and old ones removed with little difficulty. Of course, this would mean that we would have to give up tracing and run the risk of having subject cards in the catalog for books that had been reclassified or withdrawn. Here we would have to weigh advantages and disadvantages against one another. ${ }^{20}$

${ }^{18} \mathrm{Cf}$. Kelley, Grace O. The Classification of Books; an Inquiry into Its Usefulness to the Reader. New York, Wilson, 1937.

${ }^{19}$ For example: country of origin would be a very useful basis, for books published in Germany in the present period, for instance, are often more important for this fact itself than for their subject matter. Classifying books first by country of origin, then by year of publication, and then alphabetically by author, would be extremely useful from several points of view, besides the fact that it would be permanent and would also enable one to find a specific book in the stacks without first looking up a call number in the stacks without first looking up a call number classification based on subject.

${ }_{20}$ We could, of course, leave call numbers off the subject cards altogether and require the user to refer to the author-title catalog to get the call number. The inconvenience of this would not be so great as might be supposed, for it has been shown that the subject cards are used much less than the author-title cards.

\section{Pamphlets and Similar Materials}

The treatment and servicing of pamphlet and other research material that does not warrant regular cataloging has always been a problem. However, under the proposed reorganization with the reference librarians responsible for the subject cataloging and the subject approach to the material in their respective fields, whether listed in the subject card catalog or not, this material can simply be arranged in groups corresponding to the various subject fields and each reference librarian made responsible for his part of the collection. Since this type of material will not be listed in the author-title catalog, it can go directly to the reference librarians who can supervise its shelving in a special room or section of the stacks and make whatever special lists or indexes may be necessary. In time these collections will develop into what may be called research collections and will include a great deal of material that belongs much more properly in such a collection than in the general stacks. ${ }^{21}$ For this type of material, then, the reference librarian, with the help of his shelf arrangement, actually takes the place of the subject catalog. And it is quite probable that he will be of more help

21 The decision as to what sort of material does belong in such a research collection presents some difficulty. It is possible, however, in a university library to draw a distinction between "reference" material and "research" material. The former is material that is still referred to by specific references and is still important for the original purpose for which it was written. The second is material that is not referred to by specific reference and which has lost its originally intended significance and is important for some other reason-as a roth century textbook on chemistry, important now only in the study of the history of education. The former material should be fully cataloged and shelved in the general stack, the latter need not be cataloged by individual pieces and may well be housed together in a room apart from the stacks where it is available to research workers only. The recognition of this to research workers only. The recognition of this distinction and the possibility of treating "research" material without regular cataloging will enable the
library to be more liberal in its collecting policy and thereby solve another of its vexing problems. Cf. Taube, Mortimer. "The Theory of Book Selection, pt. I." College and Research Libraries 2:221-25, June 1941; also "The Realities of Library Cooperation." Library Quarterly 12:246-56, Apr. 1942. 
to research workers than any subject catalog could ever be.

There is a further responsibility that the reference librarians will be in an excellent position to assume - that of suggesting new titles for purchase in their fields. It is conceivable that each reference librarian might, in fact, act as the library representative for an academic department or two or more related departments and review their recommendations for new acquisitions before they are passed on for ordering. ${ }^{22}$ In general, each reference librarian could function as a liaison agent between the faculty and graduate students of his department or departments. ${ }^{23}$

\section{Conclusion}

It may seem, then, from one point of view that we have proposed to solve the cataloging problem by eliminating the catalog department. From another point of view, however, we have greatly extended the cataloging function so that it takes in the bibliographical checking process preparatory to ordering on the one

${ }_{22}$ All recommendations for purchase, however, will ultimately have to go through the hands of one person in general charge of book selection to insure proper coordination.

proper coordination. separate provisions have been made for the general education needs of undergraduates. hand and extends over into the work of the reference department on the other. At any rate, whatever the new arrangement does to the traditional cataloging department, it assigns a new importance to cataloging itself and makes it a more integral part of the library's work.

The foregoing presentation of the proposed reorganization must, of course, be considered as an outline that includes only the basic steps of the processes involved. Many details remain to be worked out before it can be put into practice and once the reorganization has been made, further adjustments will be necessary.

It is true that the proposed reorganization will help reduce library administrative costs and that this will be an even more important factor in the immediate future than it is now. Economy, however, has not been the primary reason for proposing the reorganization. The ultimate purpose of the reorganization is the improvement of university library service to the faculty and advanced students, by making the contents of the library accessible from the point of view of the scholar. The aim is to provide, not a librarian's library that the scholar may learn to use, but a scholar's library administered by the librarian. 